\title{
The New Era Workplace Relationships: Is Social Exchange Theory Still Relevant?
}

\author{
Lily Chernyak-Hai and Edna Rabenu \\ Netanya Academic College
}

\begin{abstract}
In this article, we argue that changes in workplace characteristics over the last few decades may affect work relationships and call for adjustments in the traditional theoretical framework used to understand them. Since the last quarter of the 20th century, there have been theories regarding changes in labor relationships following technological, political, globalization, and economical changes. However, we examine the changes in light of psychological theories rather than labor or industrial approaches. We review four main areas where social exchange theory (SET) has been implemented, address recent changes that challenge the traditional SET perspective, and propose alternative models. We refer to these models as "hybrid" as they integrate traditional SET premises with new-era workplace characteristics. First, we describe several changes in workplace characteristics. Next, we review some of the most conventional applications of SET to work relationships. Finally, we critically examine whether this theory meets the requirements of work relationships in the new world of work and conclude by arguing that SET needs to be adjusted to reflect the assumption that frequent changes in employee and organizational characteristics in the new workplaces require similar frequent adjustments in exchange relationships.
\end{abstract}

Keywords: workplace relationships, social exchange theory (SET), leader-member exchange (LMX), organizational support, OCB, CWB

The workplace has changed tremendously over the past few decades. Overall, these changes may be classified into three categories: workplace characteristics, forces operating on organizations, and management skills (Daft, 2008). The first category addresses types of resources, work, and the employees. Although "traditional" workplace resources used to be "atoms" or physical assets, the new workplace assets may be more properly characterized as "bits" of information. Further, the nature of work itself

Lily Chernyak-Hai, School of Behavioral Sciences, Netanya Academic College; Edna Rabenu, School of Behavioral Sciences, Netanya Academic College.

The authors contributed equally to this work.

Correspondence concerning this article should be addressed to Lily Chernyak-Hai, School of Behavioral Sciences, Netanya Academic College, P. O. Box 120, Netanya 4223587, Israel. E-mail: lilycher@netanya.ac.il 
has changed, becoming much more flexible and virtual. Finally, employee characteristics have changed, with greater freedom in employment (e.g., free agents, freelancers, etc.) and, particularly, the growing phenomenon of knowledge workers who now comprise at least one-quarter of the entire US workforce (Davenport, 2013).

The second category addresses forces operating on the organization, such as technology, markets, workforce, values, and events. The new workplace is digital and business oriented, as opposed to the mechanical manufacturing nature of the traditional workplace. The pros and cons of enhanced digitization have been intensively debated over the past several years. For example, due to the new technologies (e.g., shared database platforms), modern employees are able to exchange information despite geographical distance, and each has free access to knowledge repositories. Yet, technology per se does not ensure that employees will share the knowledge (Cabrera, Collins, \& Salgado, 2006).

Specifically, enhanced digitalization is said to undermine the value of traditional human labor given the growing sophistication of new technologies, which favors the employment of tech-savvy individuals (e.g., Briken, Chillas, Krzywdzinski, \& Marks, 2017). The implications of the devaluation of traditional knowledge and expertise are straightforward: lower employee status and job certainty. In other words, modern employees' potential loss is double: They compete with advanced technologies as well as with candidates skilled in applying them. Briken et al. (2017) aptly call this "digital despotism" (p. 5).

Furthermore, the current workplace is more global, and its workforce is more diverse. Organizational values have also changed, with greater emphasis on frequent change and agility over stability, sometimes at the cost of efficiency. Finally, the current organizational environment is much more dynamic and complex. This somewhat chaotic workplace, often referred to as VUCA (volatility, uncertainty, complexity, and ambiguity; see Bennett \& Lemoine, 2014), is a stressful environment for employees, especially managers, because they have less influence on organizational outcomes.

The third and last category-management skills-encompasses leadership, work methods, interpersonal relationships, and workplace design. Today's leadership is more decentralized and empowering. Moreover, whereas the old management used to be focused on profits, the new management focuses more on customer and employee relations (Daft, 2015). Today work is performed by teams more than by individuals, and workplace relationships are (ideally) more collaborative than competitive. In addition, it requires changes in the organizational structure toward a more organic structure that involves teamwork, information sharing, decentralization of decision making, and a looser hierarchy (Daft, 2015). Workplace design used to be 
characterized by emphasis on efficient performance, but the present design reflects greater emphasis on experimentation, learning, and development.

\section{Social Exchange Theory's Perspective on Work Relationships}

Although psychologically work relationships may be addressed as any kind of interpersonal relations, in the workplace they relate to both the individual and the organization. More specifically, in organizational contexts work relationships are part of the socialization process, a source of information required for successful performance and satisfaction, and a ground for social support and networking. Employees are motivated to develop positive relations at the workplace. In the process, however, they need to endure the dynamic and unpredictable challenges of today's work environment (see Leana \& Barry, 2000).

A key paradigm in examining workplace relations is social exchange theory (SET). Its basic premise is that human relations are formed based on subjective cost-benefit analysis, so that people tend to repeat actions rewarded in the past, and the more often a particular behavior has been rewarded, the more likely its recurrence (Homans, 1958). SET claims that social relationships are based on the trust that gestures of goodwill will be reciprocated (Blau, 1964). It has been applied in much of organizational research. For example, a recent meta-analysis of 25 years of organizational justice research indicates that SET variables such as trust, organizational commitment, perceived organizational support, and leader-member exchange are important to relations among justice, task performance, and citizenship behavior (Colquitt et al., 2013).

Our main research question is whether SET's implications for the understanding of work relationships need to be adjusted according to two aspects: (a) the characteristics of the new workplace; and (b) the characteristics of modern human labor of all types, including those traditionally employed within the organization, knowledge workers, and freelancers. Below, we review four main areas where SET has been mostly implemented and address recent changes that challenge it. We propose hybrid models integrating traditional SET propositions with those derived from the reviewed changes.

Note that the challenges outlined below are relevant mainly to Western culture. Culture prescribes personal values, shapes individual motives, and sets the direction of behavioral choices (see Tziner, Fein, \& Oren, 2012). To name one type of cultural difference, past research has described the difference between Western and East Asian cultures as that between individualist and collectivist (Hofstede, 1991; Triandis, 1996). For example, relationships with other individuals in East Asian cultures are perceived as fundamental for career success (see Oh et al., 2014). We elaborate on potential cultural differences and their importance for further study in the Discussion, but fully 
addressing potential cultural differences in analyzing the present applicability of SET is beyond the present scope of this article.

\section{Leader-Member Exchange}

Leader-member exchange (LMX) refers to the quality of the relations between leaders and group members. High-quality LMX indicates high levels of information exchange, interaction, trust, respect, support, mutual influence, and rewards (Bauer \& Green, 1996). LMX is said to affect employees' motivation in different areas of organizational functioning, increasing or decreasing opportunities, sense of empowerment, emotional support, and cooperative interactions, as well as loyalty, respect, and obligation (e.g., Gomez \& Rosen, 2001; Ilies, Nahrgang, \& Morgeson, 2007; Tziner et al., 2012; Waismel-Manor, Tziner, Berger, \& Dikstein, 2010).

The applicability of the traditional LMX conceptualization is challenged by the new work relationships. In some workplace contexts, LMX does not take the same form as in the past, whereas in others it is completely irrelevant. First, the job market has come to be dominated by freelancers (Weil, 2014). For example, Neuner (2013) contends that by 2020 more than $40 \%$ of the US workforce would be freelancers. Freelancers' freedom from organizational hierarchies comes at the cost of experiencing less job security and weaker identification with the corporate culture on the part of the employee and less committed workers from the organizational perspective.

A similar state of affairs applies to outsourcing. Organizations increasingly outsource in order to (a) save labor costs, (b) maintain a steady flow of employment over time despite seasonal fluctuations, and (c) benefit from specialized skills or equipment absent in the organization (Antonietti \& Cainelli, 2008). Together with freelancing, outsourcing results in many employees not being an integral part of the organization and not being directly supervised.

Another related phenomenon that may require revision of the LMX approach is knowledge workers. These tend to enjoy high autonomy (Davenport, 2013; Pink, 2001) and be unwilling to accept authority regarding the way work is performed (Davenport, 2013). Knowledge workers require management techniques that enable their performance. Therefore, their appraisal of LMX's quality may be influenced more by the degree of perceived autonomy, trust, and respect, and less by mutual influence. This is also related to the growing flexibility in working hours and the related growing tendency to work from home or in multiple company premises (Kelliher \& Anderson, 2008). These employees are also subject to relatively little direct supervision. Finally, in knowledge-based organizations where the managers are not necessarily familiar with new technologies and where the hierarchy is flat, each manager may be responsible for more employees but less involved 
in their actual performance. This state of affairs diminishes leader-member interactions.

Briken et al. (2017) raise an additional concern following the digitalization of the new workplace, which has implications for employee-supervisor relations. In the modern workplace, supervisors are increasingly able to monitor and control not only their customers and suppliers but also their employees. This may be done either via technological performance management or via social media. Even if such monitoring is legitimized, it may undermine employees' sense of trust. For example, monitoring might be augmented when workers engage in social activities using company computers. What is the right balance between employees' use of their own devices for work purposes (BYOD) and their entitlement to privacy when using company computers for nonwork purposes? Such dilemmas, although partly addressed by laws and company regulations, illuminate the need to consider the trust between employees and supervisors and the overall quality of their relationships in the new era.

Finally, the technological innovations of the last several decades have brought about the globalization of the work environment. Managers' ability to influence employees in face-to-face interactions has remarkably diminished. Employees often work on the same project at different sites, sometimes as part of international cross-cultural teams, requiring managers to influence their employees remotely. Remote employees' organizational commitment is compromised by the physical distance between them and their employers, and by the necessarily longer process of socialization to a specific organization. Accordingly, Wiesenfeld, Raghuram, and Garud (1999) argued that the most important element of managing employees in the virtual world of employment lies in creating an organizational culture through which employees could define their relatedness to the workplace despite the geographical distance.

The traditional patterns of bargaining and workplace norms are also subject to change, as managers need to cope with cultural diversity (Debrah $\&$ Smith, 2003). On the one hand, due to the competitive pressures of globalization, present-day organizations embrace diversity because of its potential to increase productivity and competitive advantages (Lockwood, 2005). Consequently, they require leaders with enhanced interpersonal communication and supervisory skills (Cascio, 2000). On the other hand, different groups have different needs that should be recognized and met, so that LMX in a given workplace may still be different for specific employees.

Globalization has dovetailed with the advent of Y-generation employees (born after 1980; also called Millennials). Millennials present a challenge to LMX, as they are likely to have different perspectives on supervisoremployee relationships (Myers \& Sadaghiani, 2010). They expect close 


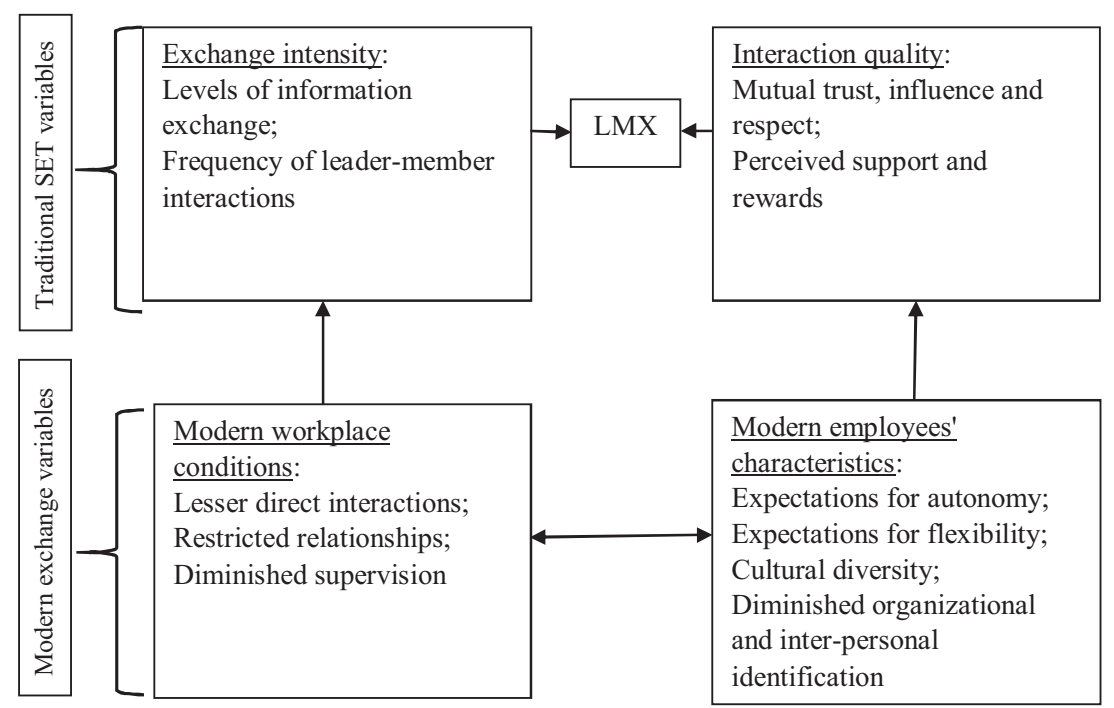

Figure 1. Proposed model of factors influencing modern leader-member exchange (LMX) and their interrelations.

relationships and open communication with supervisors, even about matters normally reserved for more senior employees (Gursoy, Maier, \& Chi, 2008; Martin, 2005). They also want high autonomy: They seek challenging tasks and have a desire to gain knowledge by working with others (Meier \& Crocker, 2010). They wish to be treated on an individual basis and need to be motivated through constant rewarding and recognition (Meier \& Crocker, 2010). Finally, Millennials are more comfortable with frequent changes in the workplace and may therefore develop less long-term relationships with their managers-a point also relevant to organizational loyalty, as discussed below.

\section{The Hybrid Model of Leader-Member Exchange}

The cultural diversity of the new workplace challenges social and organizational identifications. Managers and employees may find themselves needing to sustain relations while recognizing noticeable differences in values, norms, or customs. Accordingly, factors traditionally considered important to LMX, such as employee motivation, sense of empowerment, and organizational commitment, may now be more affected by employee perceptions of their objective job requirements and aspirations than by relationships with their direct supervisors.

Therefore, we propose an alternative model that integrates traditional SET premises with factors assumed to affect the modern LMX and their interrelations (see Figure 1). Specifically, we suggest that levels of information 
exchange and intensity of leader-employee interactions on the one hand, and levels of leader-member mutual trust, influence, respect, perceived support, and rewards (traditional SET variables) on the other still have direct implications for LMX. We also consider additional factors of the new workplace that influence LMX indirectly via their effects on traditional SET variables.

In sum, the proposed model reflects the following propositions:

1. Modern workplace conditions that include fewer direct interactions with the leader, limited leader-employee relationships, and diminished supervision affect the intensity of information exchanges and other leader-employee interactions.

2. Modern employees' characteristics, which include high expectations for autonomy and flexibility, cultural diversity, and weaker organizational identification, affect interaction quality, leader-member mutual trust, influence, and respect, as well as perceived support and rewards.

3. Modern workplace conditions and modern employees' characteristics are interrelated: The nature of the modern work environment modifies the employees' perceptions and expectations. Conversely, modern employees' characteristics require specific workplace conditions.

\section{Organizational Support and Loyalty}

Another key area where SET is applied is perceptions of organizational support and loyalty (e.g., Eisenberger, Huntington, Hutchison, \& Sowa, 1986; Scholl, 1981). Eisenberger et al. (1986) suggest that employees form a general belief regarding the extent to which the organization values their contributions and cares about them, that is, "organizational support." Higher obligation to contribute to the organization may be expected under high levels of perceived organizational support. Moreover, perceived organizational support is said to be associated with trust that the organization would reward employees for meeting their exchange obligations (Homans, 1961). Employees who perceive that their organization does not meet expected obligations would be less satisfied with their workplace experience (e.g., Tekleab, Takeuchi, \& Taylor, 2005).

This idea bears on the diverse workplace and its effect on workplace relationships, which we now examine in light of the contextual implications of equal employment opportunity laws and affirmative action practices (e.g., Holzer \& Neumark, 2000; Kalev, Dobbin, \& Kelly, 2006; Kaplan, Wiley, \& Maertz, 2011). Affirmative action is not only popular (Holzer \& Neumark, 2000), but there is growing evidence that modern organizations welcome the diversity it brings (Lockwood, 2005).

On the other hand, enforcement of equal opportunity laws may undermine relations between the employee and the organization. This is more 
likely in case of minority applicants who have only recently received legal protection, so that their social disadvantage is not yet integrated into the organizational perception of beneficial diversity. For example, the law prohibits the discrimination of disabled employees. However, this "force" operating on employers may affect their relationship with the now protected disabled employees. Rabenu and Tziner (2016a) argue, for instance, that although employers expect job applicants to reasonably present their skills and achievements, the law "mistreats" them to a degree by not requiring applicants to fully disclose the accommodations that have helped them with their scholastic or selection tests. This is particularly important in the case of so-called "invisible disabilities" (Santuzzi, Waltz, Finkelstein, \& Rupp, 2014) that may compromise employers' ability to make rational and well-informed selection decisions. Conversely, the law may set the ground for job failure as the relationship between the candidate and future employer starts on the wrong foot due to lack of transparency.

Moreover, in order to enforce the law, the courts occasionally interfere in exchange relations between the employee and the organization. For example, a teacher in a tenure position whose performance has recently dropped due to burnout cannot be terminated. Such a state of affairs will probably not be perceived as fair exchange relations by either party. A converse example is a teacher who has reached the legal retirement age and despite being much appreciated is required by law to retire.

On a more positive note, modern organizations are also more flexible in their recruitment and rewarding policies. Many now encourage friendbrings-friend recruitment, which makes organizational relationships more personal and intimate. This may contribute in turn to high perceptions of organizational support and to increased loyalty. Also, there is a variety of rewards that enable higher perception of organizational support. Some organizations base their rewards solely on salary levels, whereas others offer courses and workshops on a range of subjects (e.g., quitting smoking or dietary habits) or special insurance policies. Accordingly, modern rewards may be perceived as a facet of overall organizational support, beyond tangible merits. An example is HP-Indigo, a provider of digital printing solutions that occasionally invites retired employees to witness the latest innovations. Such actions are perceived as gestures of respect that may also contribute to the organizational commitment and loyalty of current employees.

Finally, additional characteristics of modern workplace that need to be considered relate to the previously mentioned issue of digitalization. The new workplace is said to reproduce and reinforce employee inequality. Sophisticated technologies require creativity and innovation. This means that a particular type of employee is preferred so a reputation as possessing these qualities becomes highly important (see Briken et al., 2017). Accordingly, 
employees who would be traditionally considered qualified may find themselves at a disadvantage if they are not technologically oriented. Moreover, the flexible work arrangements characteristic of the new era are generally perceived as a job reward. However, they increase the number of working hours outside the workplace. For employers, this means they do not have to pay for extra hours (Golden \& Wiens-Tuers, 2008). For the employees, beyond the flexibility provided by working from home, this also offers opportunities to develop and maintain contacts and gain higher professional experience, via establishing independent relationships and cooperation with parties beyond the immediate organizational context.

\section{The Hybrid Model of Perceived Organizational Support and Loyalty}

Overall, the aforementioned examples demonstrate that in the new workplace, perceived organizational support and loyalty are shaped not only by unmediated workplace interactions bearing on workplace exchange relationships but also and increasingly by factors related to formal legislation, specific policies of recruitment and compensation, and technological considerations. For example, high flexibility in recruitment and reward policies may lead the organization to broaden the scope of employees' contributions perceived as valuable and rewarded accordingly (we may call it "organizational sensitivity," addressed in past research as "perceived organizational support" [POS]; e.g., Eisenberger et al., 1986). In such a case, the employees are not "measured" only by their immediate productivity but also by their overall contribution to the organizational environment. This may be manifested in recruiting friends with high potential; writing in a forum or a blog in a way that contributes to higher employer branding; offering a wide range of skills, workstyles, and areas of expertise; and embodying organizational compliance with social norms such as being a socially disadvantaged employee.

Accordingly, we propose an alternative model that integrates traditional SET premises with modern factors which may be assumed to bear on perceived organizational support and loyalty (see Figure 2). Specifically, we suggest that the extent to which the organization values the employees' contributions, organizational caring, and support on the one hand and the employees' trust that the organization will fulfill its exchange obligations on the other still have direct implications for perceived organizational support and employee loyalty. Yet, we consider factors relevant to the modern workplace that influence these perceptions indirectly.

This model reflects the following propositions:

1. Modern workplace conditions, including high flexibility in recruitment, rewards and compensation policies, and the appreciation of nontangible merits reflect "organizational sensitivity"-the extent to which the 


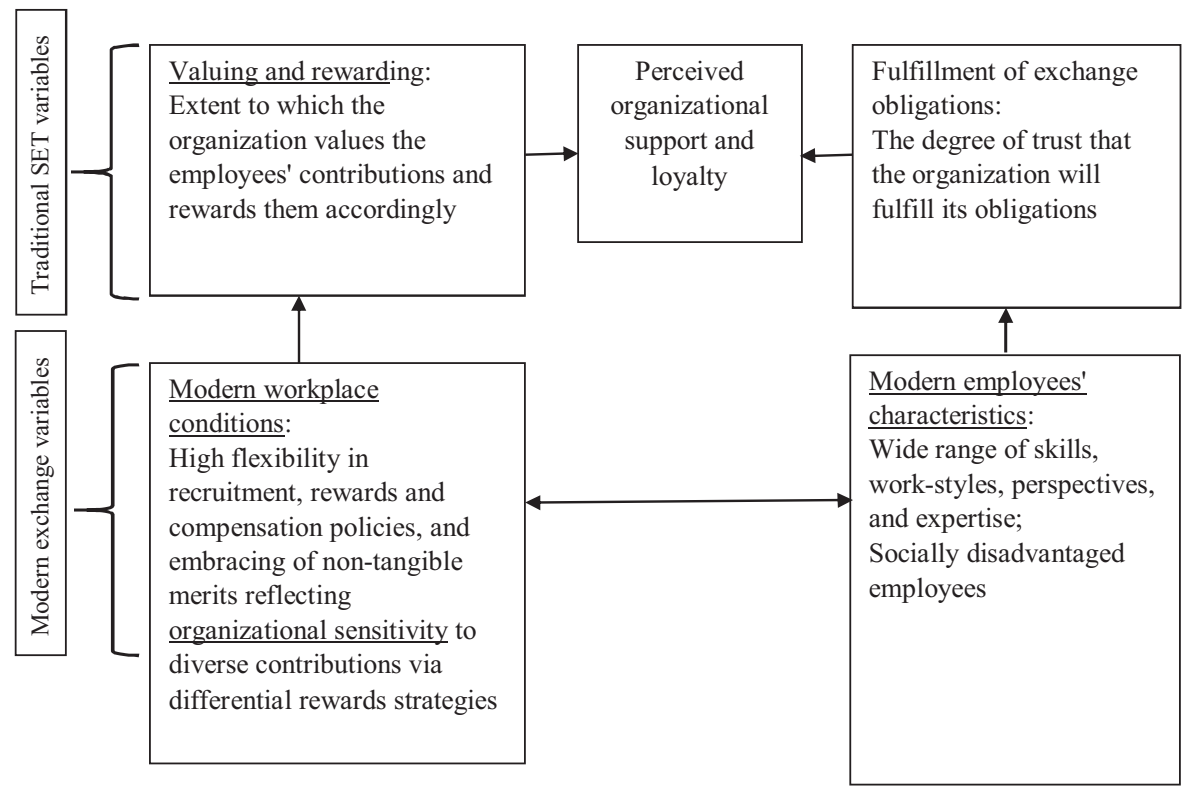

Figure 2. Proposed model of factors influencing perceived organizational support and loyalty in a modern workplace and their interrelations.

organization is sensitive to contributions of diverse workers and influences the perceived adequacy of the rewards by the new-era employees.

2. Modern employees' characteristics encompass a wide range of skills, workstyles, perspectives, and areas of expertise, and influence the perceived compliance with exchange obligations of the new-era employees.

3. Modern workplace conditions and modern employees' characteristics are interrelated. Divergent skills, workstyles, perspectives, and expertise, as well as socially disadvantaged employees' needs, require high flexibility in recruitment, reward, and compensation policies. On the other hand, flexibility in recruitment, reward, and compensation polices allow further inclusion of diverse skills, workstyles, expertise, and so on.

\section{Perceptions of Organizational Politics}

Perceptions of organizational politics are employees' perceptions of power games played by individuals or groups within the organization, designed to promote individual or collective goals that run counter to broader organizational goals or the interests of other individuals (Bozeman, et al., 1996; Drory, 1993; Elron \& Vigoda-Gadot, 2006; Ferris et al., 1996; Vigoda, 2000). Such actions include concealing valuable information, lobbying, favoritism, and taking credit for others' contributions (Elron \& Vigoda-Gadot, 2006). Previous research has reported negative associations between perceptions 
of organizational politics and behaviors that could otherwise benefit the organization such as trust in the leader (Poon, 2006), frequent interactions with coworkers (Witt, Hochwarter, \& Kacmar, 2000), perceived ability to deal with organizational challenges (Vigoda-Gadot \& Drory, 2006), high performance (Vigoda, 2000; Witt, 1998), job engagement (Cropanzano, John, Alicia, \& Paul, 1997), and satisfaction (Ferris \& Kacmar, 1992).

Performance appraisal is a good example of how changes in the workplace affect the perception of organizational politics. This common practice was originally designed to improve work relations between supervisors and employees. Using a performance appraisal system based on clear and universal standards can prevent bias in promotion and termination decisions and enable employees to better understand better their supervisors' expectations. A good appraisal system may thus contribute to a climate of mutual trust, good communication, and cooperation because it is based on a performance appraisal interview where both sides communicate about the employee's performance (Tziner, 2002).

However, in a comprehensive review of the problems of performance appraisal in organizations, Adler et al. (2016) highlight its political aspects, with raters systematically manipulating ratings to achieve a variety of goals, such as getting more money for their employees, or conversely teaching them a lesson. As the evaluation process is performed by humans, it is by nature prone to bias. Therefore, in practice, performance appraisals do not necessarily lead to improved human relations (Cappelli \& Tavis, 2016; Culbertson, Krome, McHenry, Stetzer, \& van Ittersum, 2013; Tziner, 2002). Moreover, managers tend to use performance appraisals in order to promote political interests such as assuring a peaceful work atmosphere by inflating appraisals or administrative goals such as terminating undesirable employees regardless of their actual performance (Rabenu \& Tziner, 2016b).

\section{The Hybrid Model of Perceived Organizational Politics}

The aforementioned changes in the modern workplace have made it much more difficult to assess employee performance. Modern managers are often not versed in their employees' actual work. As they rise through the hierarchy, they move away from professional expertise. Especially in the hightech industry, they are often no longer familiar with new technologies and may even lack the relevant technical skills. Their deteriorating self-efficacy as appraisers may lead them to more "political" appraisals (Bernardin \& Villanova, 2005; Tziner, 2002; Wood \& Marshall, 2008). Similar problems derive from the growing autonomy given to employees through flexible work arrangements that reduce managers' familiarity with their workplace behaviors. 


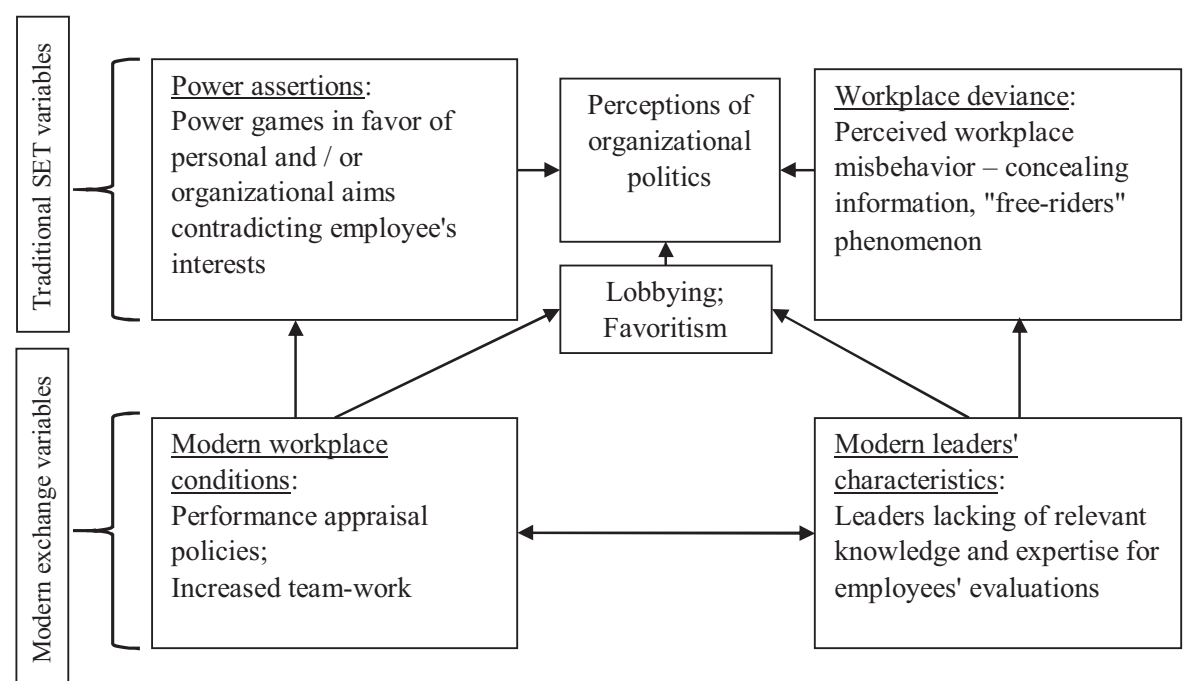

Figure 3. Proposed model of factors influencing perceived organizational politics in a modern workplace and their interrelations.

One of the solutions is to conduct peer appraisals, given the growing tendency for teamwork (Daft, 2015). Yet, team-based assessments may lead to politically biased appraisals due to logrolling or envy, or they may strengthen the power of the group vis- à-vis the supervisor so that employees feel accountable to their teammates and themselves more than to a relatively distant manager (Houghton, 2010).

In sum, here again the characteristics of modern organizations such as performance appraisals make an additional contribution to the perceptions of organizational politics beyond more direct evidence of concealing information, lobbying, or taking credit for others' contributions. In Figure 3, we outline the proposed model that incorporates modern workplace forces relevant to perceived organizational politics along with traditional SET propositions. This model includes the suggestions that perceptions of organizational politics are influenced by power games, perceived workplace misbehavior, and the phenomena of lobbying and favoritism. Yet, we claim that in the new workplace there are additional factors that affect these perceptions indirectly. This model reflects the following propositions:

1. Modern workplace conditions that include performance appraisal policies and increased teamwork influence the prevalence of power assertions-lobbying, favoritism, and belief in the frequency of power games.

2. Modern leaders' lack of specific knowledge and expertise for employee evaluations has additional implications for lobbying and favoritism, as 
well as for workplace deviance-organizational misbehavior such as concealing information and free-riding.

3. Modern workplace conditions and modern leaders' characteristics are interrelated. Leaders' lack of specific knowledge and expertise for employee evaluations modify the nature of performance appraisal policies, whereas increased teamwork distances the leader from unmediated knowledge and expertise.

\section{Organizational Citizenship Behavior and Counterproductive Work Behavior}

Organizational citizenship behavior (OCB) refers to individual actions that benefit the organization by contributing to its environment and functioning even when not formally required (e.g., Organ, Podsakoff, \& MacKenzie, 2006; Podsakoff, MacKenzie, Paine, \& Bachrach, 2000; Rotundo \& Sackett, 2002). They include altruistic helping, additional work hours, cooperation and conflict resolution, respecting others' rights, following rules and regulations, and not complaining about trivial issues (Srivastava \& Saldanha, 2008). OCB antecedents have been attributed by a considerable body of research to employee perceptions of the nature of workplace exchange relations, or the "sociopsychological" ground of OCB: perceptions of organizational justice, organizational politics, and LMX (see Chernyak-Hai \& Tziner, 2014).

Counterproductive work behavior (CWB), on the other hand, is defined as "any intentional behavior on the part of an organizational member viewed by the organization as contrary to its legitimate interests" (Sackett \& De Vore, 2001, p. 145; see also Cohen-Charash \& Mueller, 2007; Ho, 2012; Levine, 2010). CWB has gained much research attention because it has been shown to have important economical, sociological, and psychological implications (Aubé, Rousseau, Mama, \& Morin, 2009; Bodankin \& Tziner, 2009). CWBs such as theft, sabotage, withdrawal, harassment, and drug abuse violate organizational norms, compromise organizational goals, and jeopardize the overall well-being of employees. A recent study (Chernyak-Hai \& Tziner, 2014) found negative relations between perceived organizational justice and ethical climate on the one hand and CWB on the other. Moreover, the quality of workplace relations between leaders and employees was found to moderate the impact of perceived organizational distributive justice regarding CWB. A possible explanation provided for the role of LMX is that employees experiencing fair and open interaction with their leaders may avoid occasions where counterproductive behavior is possible, even if otherwise motivated to pursue it (Chernyak-Hai \& Tziner, 2014).

Thus, the social exchange antecedents of both OCB and CWB relate to different facets of LMX and perceptions of organizational politics and support. The importance of fairness was thoroughly conceptualized by Adams $(1963,1965)$, who argued that perceptions of inequality reflect a person's 
belief that the ratio of his outcomes to inputs and the ratio of other's outcomes to other's inputs are unequal. This may occur under the following conditions: (a) when the person and the other are in a direct exchange relationship or (b) when both are in an exchange relationship with a third party. In the organizational context, employees make distinct evaluations regarding the fairness of the outcomes they receive. Perceived unfairness may undermine OCB following impaired organizational identification and loyalty translated into overall unwillingness to contribute to the organization beyond what is formally required; it may also lead to CWB as a form of revenge. An important point raised by Adams (1965) was that inequity perceptions may be evoked not only when employees perceive themselves to be relatively disadvantaged (e.g., underpaid) but also when their employment status is relatively high (e.g., overpaid). Therefore, certain employees will experience unfairness when their inputs are low but their rewards are high.

The new workplace is characterized by additional sources of unfairness perceptions. In many organizations, employees of different generations (X, Y, Z) work side by side. Their ages and wages are different although their job requirements may be the same. Often, tenured employees work alongside new employees and earn a significantly higher salary, although the latter perform better, raising issues of distributive justice and potentially encouraging counterproductive behaviors.

Similar problems in work relations arise when differently compensated individuals work in the same team or on the same project. For example, one employee may be employed though a contractor, but another's terms of employment are stipulated in a more rewarding collective contract. Relatedly, as organizational commitment and a climate of trust are the cornerstones of workplace relationships, if the organization offers only short-term commitment, it may expect more rickety relationships. Under these circumstances, we may predict higher turnover and lesser OCB, excluding situations where the employee decides to prove his or her merit to improve employment terms. The following story illustrates this point. Two sisters worked in a school; one was an adjunct teacher and the other had tenure. When their mother died, the principal posted an obituary expressing condolences only to the tenured sister since she was a permanent staff member.

In the new workplace, employees are often terminated following mergers, downsizing, and so forth, but immediately reemployed through contractors, and thus they do the same work for less pay and no security. Because job insecurity is a kind of hindrance stressor (Cavanaugh, Boswell, Roehling, \& Boudreau, 2000), individuals who experience it would feel strained and impaired in their work (Cavanaugh et al., 2000), and may eventually exhibit less OCB and more CWB. Moreover, modern organizations include an entire segment of workers who are employed by contractors, such as cleaners. This 
creates a reality of "transparent" employees. Being such an employee brings with it considerable frustration that may be manifested in CWB.

An example of a process designed to improve those relations for the benefit of all is a joint venture of HP-Indigo and ISS. ISS is a contractor that provides cleaning, catering, and security services to HP-Indigo. HP-Indigo recently discovered that many of the ISS employees know very little about the basics of computer use. Therefore, the two companies initiated a course where HP-Indigo engineers volunteered to give ISS employees computer lessons. The project was an overwhelming success and contributed to better work relationships.

Another source of perceived unfairness that has become more prevalent has to do with talents who win idiosyncratic deals (nonstandard, personalized, negotiated employment arrangements; Rousseau, Ho, \& Greenberg, 2006). Many modern organizations find themselves competing for talents (Chen, 2011; Pfeffer, 2001). On the one hand, talents are part of the organization's milieu and work relationships; on the other, they are not integral to it because they enjoy an initial advantageous position. Talents have expert power, sometimes even more than their supervisors, and may become easy targets of coworker envy (Kim \& Glomb, 2014; Lam, Van der Vegt, Walter, \& Huan, 2011). As mentioned earlier, unfairness and inequality perceptions are fruitful ground for lower OCB if not CWB.

Finally, we should address the related issue of compulsory citizenship behavior $(\mathrm{CCB})$ that has become more prevalent. Modern organizations expect employees to engage in OCBs, so that these behaviors become a norm (Alkan \& Turgut, 2015). CCB relates to formal or informal coercive actions on the part of managers and coworkers to promote extra-role behaviors by employees (Vigoda-Gadot, 2006). Yet, whereas OCB consists of goodwill gestures and spontaneous actions, CCB is coerced and may become ultimately harmful for the employees and the organization (Bolino, Turnley, Gilstrap, \& Suazo, 2010; Vigoda-Gadot, 2006, 2007). CCB may evoke high levels of job stress and burnout, stronger perceptions of organizational politics, more intentions to leave the organization, lesser OCB, and higher CWB (VigodaGadot, 2006).

\section{The Hybrid Model of Organizational Citizenship Behavior and Counterproductive Work Behavior Antecedents}

Organizational exchange relationships as antecedents of OCB and CWB receive an additional angle when addressing the new workplace. Recent changes bring with them perceptions of workplace inequality and unfairness beyond those stemming from unmediated perceptions of job characteristics and organizational climate. The phenomena of employees from different generations and talents, contractor versus collective contract employees, and 


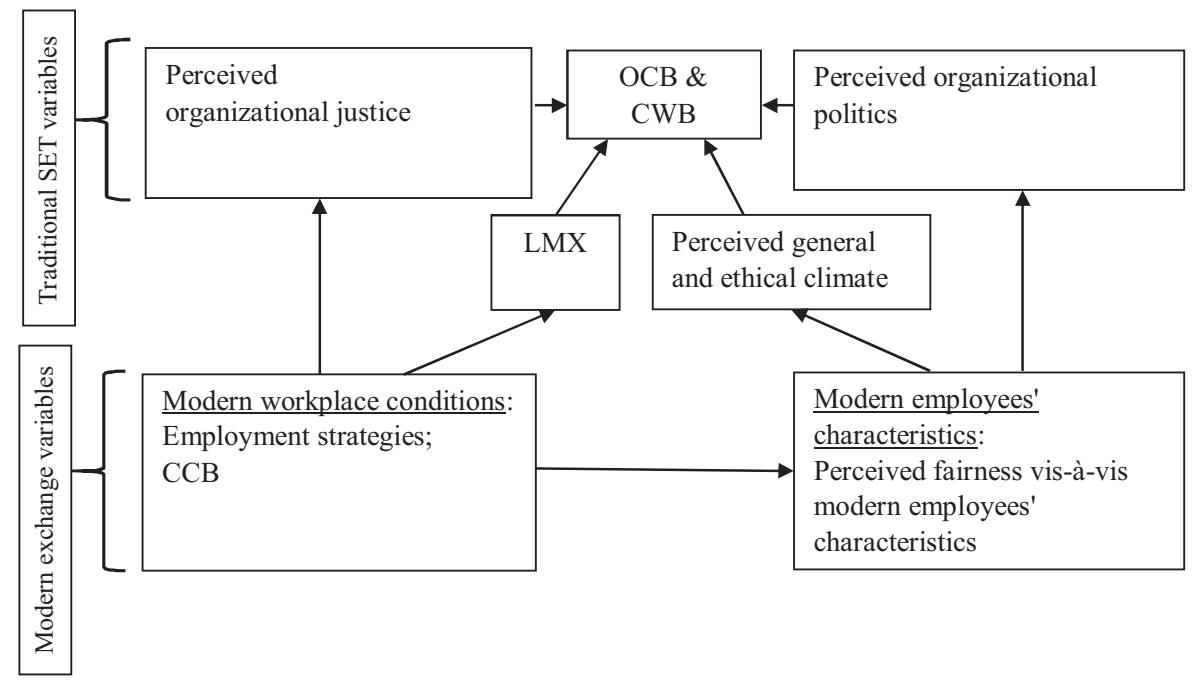

Figure 4. Proposed model of factors influencing perceived organizational citizenship behavior (OCB) and counterproductive work behavior (CWB) in a modern workplace and their interrelations.

CCB may all contribute to high levels of stress, burnout, and impaired job motivation, ultimately undermining OCB and increasing CWB.

Accordingly, we propose a model integrating SET premises on factors predicting $\mathrm{OCB}$ and $\mathrm{CWB}$ with modern workplaces characteristics (see Figure 4). The variables outlined by SET-perceived organizational justice, organizational politics, general and ethical climate, and LMX-are still important, yet we propose considering additional, new factors that affect them, as follows:

1. Modern workplace conditions reflected in employment strategies and the CCB phenomenon have implications for both LMX and perceived organizational justice.

2. Modern employees' characteristics bearing on perceived workplace fairness affect the perceived general and ethical climate and perceived organizational politics.

3. Modern workplace conditions have implications for employees' perceptions. Specifically, employment strategies and CCB influence perceived fairness.

\section{Discussion}

In this article, we reviewed key organizational contexts where SET was traditionally applied. For each, we highlighted key changes in the new workplace and the challenges they bring to traditional SET propositions. These, in turn, raised the question whether SET provided a sufficient overall 
explanation for modern workplace exchange relationships or should be adjusted. Based on the reviewed changes and specific examples, it is evident that workplace relations are still based on subjective cost-benefit analysis. However, the modern workplace offers many alternatives to traditional exchange relationships, which make it more complex, so that the same kind of exchange may be "good" or "bad" depending on organization type, employment characteristics, personal aspirations, and so on. As Briken et al. (2017) put it, the prevailing perception of "business as usual" despite the significant changes is problematic, especially as there is little consideration of imposed changes in employment patterns, skills, levels of autonomy, means of control, and so forth.

First, maintaining the same workplace exchange relationships in contexts that differ in terms of recruitment strategies, job contracts, interpersonal diversity, or global connections may arouse negative psychological reactions among employees. Second, the nature of the exchange relationship itself has changed. LMX no longer represents power and status differences as clearly as in the past but rather interactions on the same level, especially when the employee is a "talent." In addition, many freelancers' relations with their organizations do not involve direct supervision. Finally, the tendency of Generation Y employees to frequently change workplaces, laws that require organizations to hire employees of certain groups, and employees recruited directly by their friends all lead to different expectations from organizations, employers, and employees. Employers are still expected to see to their employees' development and promotion, but at the same time, employees want to be in charge of their career paths, and do not necessarily wait for the employer to do that for them. Moreover, in their relations with coworkers, they are still expected to exhibit mutual support and knowledge sharing, but in the new workplace, coworker relationships are increasingly virtual.

Furthermore, the digitization of the workplace reveals an additional consideration: the growing complexity of the human supervisor's role. It is not only that modern leaders need additional skills to manage technical tools and operations (Cascio, 2000). Where technology replaces human interactions, employees may face difficulty communicating and satisfying their needs, concerns, or aspirations. Therefore, the role of a leader in promoting employee performance and well-being is expected to become increasingly important. As opposed to technology-based supervision, human supervisors are not bound by preprogrammed routine procedures. They are capable of understanding and negotiating the multiple and often contradictory needs of their customers and employees. Accordingly, being the focal human factor in determining and/or complying with organizational policies, in coordinating the work of culturally diverse and often remote employees, and in being able 
to identify their needs, the modern LMX calls for further conceptualization beyond the traditional SET tenets.

These changes may be further analyzed using the concept of the psychological employment contract, whose importance has been extensively demonstrated in recent studies (e.g., Shore et al., 2004; Taylor \& Tekleab, 2004; Zhao, Wayne, Glibkowski, \& Bravo, 2007). The concept was suggested as a part of a framework for understanding employment relationships in terms of mutual expectations by the employer and employees (Rousseau, $1989,1995)$. The psychological contracts in the modern workplace are significantly different from those of the past. Traditionally, the basic expectation of the employees was to be industrious and committed to their job in exchange for fair treatment and job security, but in the new workplace employers are incapable of ensuring such security. Moreover, paying the salary on time and behaving respectfully are no longer enough, as employers are also required to understand their employees' specific needs, values, and customs to empower them and provide them with a broader range of rewards, which may even include the employee's family.

The psychological contract is also relevant to the more general issue of fit. According to the person-environment fit approach (Dawis \& Lofquist, 1984) as applied to the organizational context, an important antecedent of both organizational and employee well-being is the correspondence between employee characteristics, such as knowledge, values, abilities, aspirations, and needs, and workplace characteristics, such as job requirements, supplies, and rewards. The fit theory emphasizes the need for such correspondence for organizational functioning and employee satisfaction. Recently, it has become more difficult to ensure this fit, because there are many parameters that need to be taken into account. Some of the factors complicating the picture have been discussed above: whether the employee is a freelancer, whether he or she belongs to a legally protected group, whether he or she is a Generation Y member, or whether he or she works under flexible employment arrangements. All these factors must be considered even before the personal needs of a specific employee are assessed.

Increased employee diversity as it relates to various reward alternatives in a changing workplace environment makes a perfect fit (and with it, longterm employee commitment) nearly impossible. Accordingly, SET needs to be adjusted to reflect the assumption that frequent changes in employee and organizational characteristics in the new workplaces require similar frequent adjustments in exchange relationships. Uniform exchange relationships can no longer "deliver," and we may expect to see more and more personally specified contracts for talents and other professionals.

Organizations must understand that the changing nature of workplace exchanges has far-reaching effects. For example, recent research has found 
significant differences in knowledge sharing between employees in accordance with the type of their employment contract (Koriat \& Gelbard, 2014, in press). Specifically, external workers employed through service contractors, outsourcing, or as advisers or freelancers felt less identified with the organization and its goals compared to internal workers and tended to exhibit less knowledge sharing. Accordingly, Koriat and Gelbard (2014) concluded that organizations should also pay attention to human resource practices concerning all types of employees in order to establish transparent and supportive relations that would in turn encourage knowledge sharing.

Finally, as workplace relationships become more personal, we may assume a greater need for enforcement of labor laws designed to prevent exploitation and maintain compliance with basic ethical standards. Managers, human resource managers in particular, must play a key role in the construction of labor relationships in the new workplace by suggesting fair exchange alternatives on the one hand while recognizing the change in employees' needs on the other.

\section{Future Research Directions}

\section{The Relevance of Personal and Cultural Values}

Considering the scope of the present article, we did not refer to specific personal and cultural values that may influence the way the employees perceive desirable relations in the new workplace. However, this is an important issue to be addressed in future studies. Values are related to needs and goals, and may function as standards affecting goal setting, decision making, and action. Personal and cultural values are particularly relevant to the concept of "person-environment fit" (Edwards, 1991), as they may determine what is perceived as fit. The degree of fit affects employees' experiences of selfefficacy, motivation, and self-regulation, and eventually work attitudes and behaviors, and assessing it is therefore essential for understanding motivational processes in organizational contexts (see model outlined by Tziner et al., 2012).

Personal values perspective. Personal values were found to have implications for various organizational factors, such as citizenship behaviors (Arthaud-Day, Rode, \& Turnley, 2012; Seppälä, Lipponen, Bardi, \& PirttiläBackman, 2012), perceptions of relational-type contracts (Cohen, 2012), workplace commitment (Cohen, 2011), and employees' reports of difficulty in balancing their work and family lives (Chernyak-Hai \& Tziner, 2016). Accordingly, we may expect employees' personal values to influence their perceptions of LMX quality, organizational support, politics, climate, $\mathrm{OCB}$, and CWB. For example, past research has shown that employees valuing power prefer transactional rather than transformational leaders (Fein, Vasiliu, \& Tziner, 2011). Such employees may have hard time adapting to the new 
reality where the interactions with the leader are less direct and supervision is diminished, as well as to workplace autonomy and flexibility (see Figure 1).

Another example is OCB. Research has shown that values of achievement, benevolence, and self-direction are positively related to OCB in teams (Arthaud-Day et al., 2012). Accordingly, it may be that employees characterized by high levels of these values will be relatively "immune" to the influences of modern workplace characteristics via their implications for organizational climate and LMX (see Figure 4).

Cultural values perspective. Cultural values add another aspect to the models proposed in this article. These values form the organizational culture. Accordingly, Oh et al.'s (2014) meta-analysis of the differences between the East Asian and North American cultural contexts indicated that relational, person-group, and especially person-supervisor fit were more central to work outcomes in East Asia. In addition, East Asian workplaces placed greater emphasis on hierarchical relationships: Employees in East Asia were expected to be loyal to their supervisors in exchange for protection and support.

The latter is relevant particularly when considering LMX. Loi, Chan, and Lam (2014) stressed the positive effect of LMX on organizational identification through employees' perceptions of the degree to which their relations with the supervisor met the needs of reduced uncertainty and selfenhancement. Therefore, we may expect that in East Asian cultures, assuring high-quality LMX will be of special importance. In light of the changes in workplace environment (see Figure 1), it will be cardinal to attain LMX reflecting mutual expectations of the employee and leader according to the cultural frame of hierarchical relationships, loyalty, and support. In addition, given the notion that there is a conceptual overlap between interactional justice and LMX following perceptions of manager fairness and positive social exchanges (see Wayne, Shore, Bommer, \& Tetrick, 2002), these expectations may be predicted to affect what is perceived by the employees as organizational climate and so influence OCB and CWB (see Figure 4).

\section{Additional SET Variables}

An interesting future direction could be to identify additional exchange variables that have become more prominent in the new workplace. For example, because much of modern work is performed in teams, a relevant variable would be "team climate"-levels of warmth, support, sincerity, and so on (Choi, Price, \& Vinokur, 2003). Future works may also address modern employees' experience of work-family conflict (Frone, 2000; Judge, Ilies, \& Scott, 2006). Highly flexible work hours and environments blur the boundaries between work and family settings. These circumstances raise further challenges in attempts to balance work and family requirements, while the 
ambiguity experienced may also negatively influence perceived organizational support, followed in turn by fewer displays of OCB and higher prevalence of CWB.

\section{Additional Theoretical Frameworks}

Finally, future studies may adopt a similar approach to that applied in the present analysis by addressing the relevance and applicability of additional organizational behavior theories. One obvious example is conservation of resources theory (COR; Hobfoll, 1988, 1998, 2001). COR theory emphasizes people's willingness to acquire and protect psychological, social, and material resources, and conversely the psychological stress experienced when those are lost or threatened, or if individuals cannot replenish them after significant investment. Such stress impairs employees' adjustment to their work environments (e.g., Xanthopoulou, Bakker, Demerouti, \& Schaufeli, 2009). We may assume that the new workplace's VUCA characteristics (Bennett \& Lemoine, 2014) require greater investment of personal resources. Accordingly, they amplify employee concerns with obtaining and/or maintaining the required resources. On the other hand, the same characteristics may decrease resource depletion (e.g., flexible work hours or working from home). Therefore, the assumptions of COR theory may be challenged in the modern workplace and require some adjustments.

\section{References}

Adams, J. S. (1963). Toward an understanding of inequity. Journal of Abnormal and Social Psychology, 67(5), 422-436. doi: 10.1037/h0040968

Adams, J. S. (1965). Inequity in social exchange. Advances in Experimental Social Psychology, 2, $267-$ 299. doi: 10.1016/S0065-2601(08)60108-2.

Adler, S., Campion, M., Colquitt, A., Grubb, A., Murphy, K., Krane-Ollander, R., \& Pulakos, D. S. (2016). Getting rid of performance ratings: Genius or folly? A debate. Industrial and Organizational Psychology: Perspectives on Science and Practice, 9(2), 219-252. doi: 10.1017/iop.2015.106

Alkan, S. E., \& Turgut, T. (2015). A research about the relationship of psychological safety and organizational politics perception with compulsory citizenship behavior and the pressures behind compulsory citizenship behavior. Research Journal of Business and Management, 2(2), 185-203. doi: 10.17261/Pressacademia.2015211506

Antonietti, R., \& Cainelli, G. (2008). Spatial agglomeration, technology and outsourcing of knowledge-intensive business services: Empirical insights from Italy. International Journal of Services Technology and Management, 10(2-4), 273-298. doi: 10.1504/IJSTM.2008.022123

Arthaud-Day, M. L., Rode, J. C., \& Turnley, W. H. (2012). Direct and contextual effects of individual values on organizational citizenship behavior in teams. Journal of Applied Psychology, 97(4), 792807. doi: $10.1037 / \mathrm{a} 0027352$

Aubé, C., Rousseau, V., Mama, C., \& Morin, E. (2009). Counterproductive behaviors and psychological well-being: The moderating effect of task interdependence. Journal of Business and Psychology, 24, 351-361. doi: 10.1007/s10869-009-9113-5

Bauer, T. N., \& Green, S. G. (1996). Development of leader-member exchange: A longitudinal test. Academy of Management Journal, 39, 1538-1567. doi: 10.2307/257068 
Bennett, N., \& Lemoine, J. (2014). What VUCA really means for you. Harvard Business Review, 92(1/2), 27-27. doi: http://ssrn.com/abstract=2389563

Bernardin, H. J., \& Villanova, P. (2005). Research streams in rater self-efficacy. Group \& Organization Management, 30, 61-88. doi: https://doi.org/10.1177/1059601104267675

Blau, P. M. (1964). Exchange and power in social life. Piscataway, NJ: Transaction Publishers.

Bodankin, M., \& Tziner, A. (2009). Constructive deviance, destructive deviance and personality: How do they interrelate? Amfiteatru Economic Journal, 11, 549-564. doi: http://ssrn.com/abstract= 1885007

Bolino, M. C., Turnley, W. H., Gilstrap, J. B., \& Suazo, M. M. (2010). Citizenship under pressure: What's a "good soldier" to do? Journal of Organizational Behavior, 31(6), 835-855. doi: 10.1002/job.635

Bozeman, D. P., Perrewe, P. L., Kacmar, K. M., Hochwarter, W. A., \& Brymer, R. A. (1996). An examination of reactions to perceptions of organizational politics. Paper presented at the Southern Management Association Meeting, New Orleans, LA.

Briken, K., Chillas, S., Krzywdzinski, M., \& Marks, A. (2017). Labour process theory and the new digital workplace. In A. Marks, K. Briken, S. Chillas, \& M. Krzywdzinski (Eds.), The new digital workplace: How new technologies revolutionise work (pp. 1-13). New York, NY: Springer.

Cabrera, A., Collins, W. C., \& Salgado, J. F. (2006). Determinants of individual engagement in knowledge sharing. The International Journal of Human Resource Management, 17(2), 245-264. doi: https://doi.org/10.1080/09585190500404614

Cappelli, P., \& Tavis, A. (2016). The performance management revolution. Harvard Business Review. Retrieved from https://hbr.org/2016/10/the-performance-management-revolution

Cascio, W. F. (2000). Managing a virtual workplace. Academy of Management Executive, 14(3), 81-90. doi: 10.5465/AME.2000.4468068

Cavanaugh, M. A., Boswell, W. R., Roehling, M. V., \& Boudreau, J. W. (2000). An empirical examination of self-reported work stress among US managers. Journal of Applied Psychology, 85(1), 65-74. doi: 10.1037/0021-9010.85.1.65

Chen, L. (2011, April 5). The changing workforce. Cornell HR Review. Retrieved from http:// digitalcommons.ilr.cornell.edu/chrr/20

Chernyak-Hai, L., \& Tziner, A. (2014). Relationships between counterproductive work behavior, perceived justice and climate, occupational status, and leader-member exchange. Revista de Psicología del Trabajo y de las Organizaciones, 30(1), 1-12. doi: 10.5093/tr2014a1

Chernyak-Hai, L., \& Tziner, A. (2016). The "I believe" and the "I invest" of work-family balance: The indirect influences of personal values and work engagement via perceived organizational climate and workplace burnout. Revista de Psicología del Trabajo y de las Organizaciones, 32(1), 1-10. doi: 10.1016/j.rpto.2015.11.004

Choi, J. N., Price, R. H., \& Vinokur, A. D. (2003). Self-efficacy changes in groups: Effects of diversity, leadership and group climate. Journal of Organizational Behavior, 24, 357-371. doi: 10.1002/job.195

Cohen, A. (2011). Values and psychological contracts in their relationship to commitment in the workplace. Career Development International, 16(7), 646-667. doi: 10.1108/ 13620431111187272

Cohen, A. (2012). The relationship between individual values and psychological contracts. Journal of Managerial Psychology, 27(3), 283-301. doi: 10.1108/02683941211205826

Cohen-Charash, Y., \& Mueller, J. S. (2007). Does perceived unfairness exacerbate or mitigate interpersonal counterproductive work behaviors related to envy? Journal of Applied Psychology, 92(3), 666-680. doi: 10.1037/0021-9010.92.3.666

Colquitt, J. A., Scott, B. A., Rodell, J. B., Long, D. M., Zapata, C. P., Conlon, D. E., \& Wesson, M. J. (2013). Justice at the millennium, a decade later: A meta-analytic test of social exchange and affect-based perspectives. Journal of Applied Psychology, 98, 199-236. doi: 10.1037/a0031757

Cropanzano, R., Howes, J. C., Grandey, A. A., \& Toth, P. (1997). The relationship of organizational politics and support to work behaviors, attitudes, and stress. Journal of Organizational Behavior, $18,159-180$. 
Culbertson, S. S., Krome, L.R., McHenry, B. J., Stetzer, M. W., \& van Ittersum, K. W. (2013). Performance appraisals: Mend them, don't end them. In M. A. Paludi (Ed.), Psychology for business success (Vol. 4, pp. 35-51). Santa Barbara, CA: Praeger.

Daft, R. L. (2008). New era of management. Mason, OH: Thomson South-Western.

Daft, R. (2015). Organization theory and design. Boston, MA: Cengage Learning.

Davenport, T. H. (2013). Thinking for a living: How to get better performances and results from knowledge workers. Brighton, MA: Harvard Business Press.

Dawis, R. V., \& Lofquist, L. H. (1984). A psychological theory of work adjustment: An individualdifferences model and its applications. Minneapolis, MN: University of Minnesota Press.

Debrah, Y. A., \& Smith, I. G. (Eds.). (2003). Globalization, employment and the workplace: Diverse impacts. London: Routledge.

Drory, A. (1993). Perceived political climate and job attitudes. Organizational Studies, 14, 59-71. doi: $10.1177 / 017084069301400105$

Edwards, J. R. (1991). Person-job fit: A conceptual integration, literature review, and methodological critique. In C. L. Cooper \& I. T. Robertson (Eds.), International review of industrial and organizational psychology (Vol. 6, pp. 283-357). New York, NY: Wiley.

Eisenberger, R., Huntington, R., Hutchison, S., \& Sowa, D. (1986). Perceived organizational support. Journal of Applied Psychology, 71, 500-507.

Elron, E., \& Vigoda-Gadot, E. (2006). Influence and political processes in cyberspace: The case of global virtual teams. International Journal of Cross Cultural Management, 6(3), 295-317. doi: $10.1177 / 1470595806070636$

Fein, E. C., Vasiliu, C., \& Tziner, A. (2011). Individual values and preferred leadership behaviors: A study of Romanian managers. Journal of Applied Social Psychology, 41(3), 515-535. doi: 10.1111/j.1559-1816.2011.00724.x

Ferris, G. R., Frink, D. D., Galang, M. C., Zhou, J., Kacmar, K. M., \& Howard, J. (1996). Perceptions of organizational politics: Predisposition, stress-related implications, and outcomes. Human Relations, 49(2), 233-266. doi: 10.1177/001872679604900206

Ferris, G. R., \& Kacmar, K. M. (1992). Perceptions of organizational politics. Journal of Management, 18, 93-116. doi: 10.1177/014920639201800107

Frone, M. R. (2000). Work-family conflict and employee psychiatric disorders: The national comorbidity survey. Journal of Applied Psychology, 85(6), 888-895. doi: 10.1037/0021-9010.85.6.888

Golden, L., \& Wiens-Tuers, B. (2008). Overtime work and well-being at home. Review of Social Economy, 66(1), 25-49. doi: 10.1080/00346760701668495

Gomez, C., \& Rosen, B. (2001). The leader-member exchange as a link between managerial trust and employee empowerment. Group and Organization Management, 26(1), 53-69. doi: $10.1177 / 1059601101261004$

Gursoy, D., Maier, T. A., \& Chi, C. G. (2008). Generational differences: An examination of work values and generational gaps in the hospitality workforce. International Journal of Hospitality Management, 27(3), 448-458. doi: 10.1016/j.ijhm.2007.11.002

Ho, V. T. (2012). Interpersonal counterproductive work behaviors: Distinguishing between personfocused versus task-focused behaviors and their antecedents. Journal of Business and Psychology, 27, 467-482. doi: 10.1007/s10869-012-9256-7

Hobfoll, S. E. (Ed.). (1988). The ecology of stress. New York, NY: Hemisphere.

Hobfoll, S. E. (1998). The psychology and philosophy of stress, culture and community. New York, NY: Plenum Press.

Hobfoll, S.E. (2001). The influence of culture, community, and the nested-self in the stress process: Advancing conservation of resources theory. Applied Psychology, 50, 337-421. doi: 10.1111/1464-0597.00062

Hofstede, G. (1991). Cultures and organizations: Software of the mind. Berkshire, UK: McGrawHill.

Holzer, H. J., \& Neumark, D. (2000). What does affirmative action do? Industrial \& Labor Relations Review, 53(2), 240-271. doi: 10.1177/001979390005300204

Homans, G. C. (1958). Social behavior as exchange. American Journal of Sociology, 597-606. 
Homans, G. C. (1961). Social behavior in elementary forms: A primer of social psychological theories. Monterey, CA: Brooks/Cole Publishing Company.

Houghton, J. D. (2010). Does Max Weber's notion of authority still hold in the twenty-first century? Journal of Management History, 16(4), 449-453. doi: 10.1108/17511341011073933

Ilies, R., Nahrgang, J. D., \& Morgeson, F. O. (2007). Leader-member exchange and citizenship behaviors: A meta-analysis. Journal of Applied Psychology, 92, 269-277. doi: 10.1037/00219010.92.1.269

Judge, T. A., Ilies, R., \& Scott, B. A. (2006). Work-family conflict and emotions: Effects at work and at home. Personnel Psychology, 59(4), 779-814. doi: 10.1111/j.1744-6570.2006.00054.x

Kalev, A., Dobbin, F., \& Kelly, E. (2006). Best practices or best guesses? Assessing the efficacy of corporate affirmative action and diversity policies. American Sociological Review, 71(4), 589-617. doi: $10.1177 / 000312240607100404$

Kaplan, D. M., Wiley, J. W., \& Maertz, C. P. (2011). The role of calculative attachment in the relationship between diversity climate and retention. Human Resource Management, 50(2), 271-287. doi: $10.1002 / \mathrm{hrm} .20413$

Katz, H.C. (1993). The decentralization of collective bargaining: A literature review and comparative analysis. Industrial \& Labor Relations Review, 47(1), 3-22. doi: 10.1177/ 001979399304700101

Kaufman, B. E. (1993). The origins \& evolution of the field of industrial relations in the United States. Ithaca, NY: ILR Press.

Kelliher, C., \& Anderson, D. (2008). For better or for worse? An analysis of how flexible working practices influence employees' perceptions of job quality. The International Journal of Human Resource Management, 19(3), 419-431. doi: 10.1080/09585190801895502

Kim, E., \& Glomb, T. M. (2014). Victimization of high performers: The roles of envy and work group identification. Journal of Applied Psychology, 99(4), 619-634. doi: 10.1037/a0035789

Koriat, N., \& Gelbard, R. (2014). Knowledge sharing motivation among IT personnel: Integrated model and implications of employment contracts. International Journal of Information Management, 34(5), 577-591. doi: 10.1016/j.ijinfomgt.2014.04.009

Koriat, N., \& Gelbard, R. (In press). Knowledge sharing analytics: The case of IT workers. Journal of Computer Information Systems. doi: 10.1080/08874417.2017.1360163

Lam, C. K., Van der Vegt, G. S., Walter, F., \& Huang, X. (2011). Harming high performers: A social comparison perspective on interpersonal harming in work teams. Journal of Applied Psychology, 96(3), 588-601. doi: 10.1037/a0021882

Leana, C. R., \& Barry, B. (2000). Stability and change as simultaneous experiences in organizational life. Academy of Management Review, 25(4), 753-759. doi: 10.5465/AMR.2000.3707707

Levine, E. L. (2010). Emotion and power (as a social influence): Their impact on organizational citizenship and counterproductive individual and organizational behavior. Human Resource Management Review, 20, 4-17. doi: 10.1016/j.hrmr.2009.03.011

Lockwood, N. R. (2005). Workplace diversity: Leveraging the power of difference for competitive advantage. HR Magazine, 50(6), 1-10.

Loi, R., Chan, K. W., \& Lam, L. W. (2014). Leader-member exchange, organizational identification, and job satisfaction: A social identity perspective. Journal of Occupational and Organizational Psychology, 87(1), 42-61. doi: 10.1111/joop.12028

Martin, C. A. (2005). From high maintenance to high productivity: What managers need to know about Generation Y. Industrial and Commercial Training, 37(1), 39-44. doi: $10.1108 / 00197850510699965$

Meier, J., \& Crocker, M. (2010). Generation Y in the workforce: Managerial challenges. Journal of Human Resource and Adult Learning, 6(1), 68-78.

Myers, K. K., \& Sadaghiani, K. (2010). Millennials in the workplace: A communication perspective on millennials' organizational relationships and performance. Journal of Business and Psychology, 25(2), 225-238. doi: 10.1007/s10869-010-9172-7

Neuner, J. (2013, March 20). 40\% of America's workforce will be freelancers by 2020. Quartz. Retrieved from http://qz.com/65279/40-of-americas-workforce-will-be-freelancers-by-2020/ 
Oh, I. S., Guay, R. P., Kim, K., Harold, C. M., Lee, J. H., Heo, C. G., \& Shin, K. H. (2014). Fit happens globally: A meta-analytic comparison of the relationships of person-environment fit dimensions with work attitudes and performance across East Asia, Europe, and North America. Personnel Psychology, 67(1), 99-152. doi: 10.1111/peps.12026

Organ, D. W., Podsakoff, P. M., \& MacKenzie, S. B. (2006). Organizational citizenship behavior: Its nature, antecedents, and consequences. Thousand Oaks, CA: Sage.

Pfeffer, J. (2001). Fighting the war for talent is hazardous to your organization's health. Organizational Dynamics, 29(4), 248-259. doi: 10.1016/S0090-2616(01)00031-6

Pink, D. H. (2001). Free agent nation: How America's new independent workers are transforming the way we live. New York, NY: Warner Books.

Podsakoff, P. M., MacKenzie, S. B., Paine, J. B., \& Bachrach, D. G. (2000). Organizational citizenship behaviors: A critical review of the theoretical and empirical literature and suggestions for future research. Journal of Management, 26, 513-563. doi: 10.1177/014920630002600307

Poon, J. M. L. (2006). Trust-in-supervisor and helping co-workers: Moderating effect of perceived politics. Journal of Managerial Psychology, 21(6), 518-532. doi: https://doi.org/10.1108/ 02683940610684373

Rabenu, E., \& Tziner, A. (2016a). Selection of employees with disabilities: Has the burden on the employer become too heavy? Amfiteatru Economic, 18(41), 423-431.

Rabenu, E., \& Tziner, A. (2016b). Performance appraisal in a constantly changing work world. Industrial and Organizational Psychology: Perspectives on Science and Practice, 9(2), 370-377. doi: 10.1017/iop.2016.28

Rotundo, M., \& Sackett, P. R. (2002). The relative importance of task, citizenship, and counterproductive performance to global ratings of job performance: A policy capturing approach. Journal of Applied Psychology, 87, 66-80. doi: http://psycnet.apa.org/doi/10.1037/0021-9010. 87.1.66

Rousseau, D. M. (1989). Psychological and implied contracts in organizations. Employee Responsibilities and Rights Journal, 2(2), 121-139. doi: 10.1007/BF01384942

Rousseau, D. M. (1995). Psychological contracts in organizations: Understanding written and unwritten agreements. Thousand Oaks, CA: Sage.

Rousseau, D. M., Ho, V. T., \& Greenberg, J. (2006). I-deals: Idiosyncratic terms in employment relationships. Academy of Management Review, 31(4), 977-994. doi: 10.5465/AMR.2006. 22527470

Sackett, P. R., \& DeVore, C. J. (2001). Counterproductive behaviors at work. In N. Anderson, D. S. Ones, H. K. Sinangil, \& C. Viswesvaran (Eds.). Handbook of industrial work, \& organizational psychology, (Vol. 1, pp. 145-164). London, UK: Sage.

Santuzzi, A. M., Waltz, P. R., Finkelstein, L. M., \& Rupp, D. E. (2014). Invisible disabilities: Unique challenges for employees and organizations. Industrial and Organizational Psychology: Perspectives on Science and Practice, 7(2), 204-219. doi: 10.1111/iops.12134

Scholl, R. W. (1981). Differentiating organizational commitment from expectancy as a motivating force. Academy of Management Review, 6, 589-599. doi: 10.5465/AMR.1981.4285698

Seppälä, T., Lipponen, J., Bardi, A., \& Pirttilä-Backman, A. M. (2012). Change-oriented organizational citizenship behaviour: An interactive product of openness to change values, work unit identification, and sense of power. Journal of Occupational and Organizational Psychology, 85(1), 136-155. doi: 10.1111/j.2044-8325.2010.02010.x

Shore, L. M., Tetrick, L. E., Taylor, M. S., Shapiro, J. C., Liden, R. C., Parks, J. M., ... Rousseau, D. M. (2004). The employee-organization relationship: A timely concept in a period of transition. Research in Personnel and Human Resources Management, 23, 291-370. doi: 10.1016/S07427301(04)23007-9

Srivastava, K., \& Saldanha, D. (2008). Organizational citizenship behavior. Industrial Psychiatry Journal, 17, 1-3.

Taylor, M. S., \& Tekleab, A. G. (2004). Taking stock of psychological contract research: Assessing progress, addressing troublesome issues, and setting research priorities. In J. A. M. CoyleShapiro, L. M. Shore, M. S. Taylor, \& L. E. Tetrick (Eds.), The employment relationship: 
Examining psychological and contextual perspectives (pp. 253-283). Oxford, UK: Oxford University Press.

Tekleab, A. G., Takeuchi, R., \& Taylor, M. S. (2005). Extending the chain of relationships among organizational justice, social exchange, and employee reactions: The role of contract violations. Academy of Management Journal, 48(1), 146-157. doi: 10.5465/AMJ.2005.15993162

Triandis, H. C. (1996). The psychological measurement of cultural syndromes. American Psychologist, 51(4), 407-415. doi: 10.1037/0003-066X.51.4.407

Tziner, A. (2002). Human resources management and organizational behavior: Selected perspectives. Aldershot, UK: Ashgate.

Tziner, A., Fein, E., \& Oren, L. (2012). Human motivation and performance outcomes in the context of downsizing. In C. L. Cooper, A. Pandey, \& J. C. Quick (Eds.), Downsizing: Is less still more? (1st ed., pp. 103-133). New York, NY: Cambridge University Press.

Vigoda, E. (2000). Organizational politics, job attitudes, and work outcomes: Exploration and implications for the public sector. Journal of Vocational Behavior, 57, 326-347. doi: 10.1006/jvbe.1999.1742

Vigoda-Gadot, E. (2006). Compulsory citizenship behavior: Theorizing some dark sides of the good soldier syndrome in organizations. Journal for the Theory of Social Behaviour, 36(1), 77-93. doi: 10.1111/j.1468-5914.2006.00297.x

Vigoda-Gadot, E. (2007). Redrawing the boundaries of OCB? An empirical examination of compulsory extra-role behavior in the workplace. Journal of Business and Psychology, 21(3), 377-405. doi: 10.1007/s10869-006-9034-5

Vigoda-Gadot, E., \& Drory, A. (Eds.). (2006). Handbook of organizational politics. Cheltenham, UK: Edward Elgar.

Waismel-Manor, R., Tziner, A., Berger, E., \& Dikstein, E. (2010). Two of a kind? Leadermember exchange and organizational citizenship behaviors: The moderating role of leadermember similarity. Journal of Applied Social Psychology, 40(1), 167-181. doi: 10.1111/j.15591816.2009.00568.x

Wayne, S. J., Shore, L. M., Bommer, W. H., \& Tetrick, L. E. (2002). The role of fair treatment and rewards in perceptions of organizational support and leader-member exchange. Journal of applied psychology, 87(3), 590-598. doi: 10.1037/0021-9010.87.3.590

Weil, D. (2014). The fissured workplace: Why work became so bad for so many and what can be done to improve it. Cambridge, MA: Harvard University Press.

Wiesenfeld, B. M., Raghuram, S., \& Garud, R. (1999). Managers in a virtual context: The experience of self-threat and its effects on virtual work organizations. In C. L. Cooper \& D. M. Rousseau (Eds.), Trends in organizational behavior: The virtual organization (Vol. 6, pp. 31-44). Chichester, UK: Wiley.

Witt, L. A. (1998). Enhancing organizational goal congruence: A solution to organizational politics. Journal of Applied Psychology, 83, 666-674. doi: 10.1037/0021-9010.83.4.666

Witt, L. A., Hochwarter, W. A., \& Kacmar, K. M. (2000). Perception of organizational politics as a moderator of the relationship between conscientious and job performance. Journal of Applied Psychology, 85(3), 472-478. doi: 10.1037/0021-9010.85.3.472

Wood, R. E., \& Marshall, V. (2008). Accuracy and effectiveness in appraisal outcomes: The influence of self-efficacy, personal factors and organizational variables. Human Resource Management Journal, 18(3), 295-313. doi: 10.1111/j.1748-8583.2008.00067.x

Xanthopoulou, D., Bakker, A. B., Demerouti, E., \& Schaufeli, W. B. (2009). Reciprocal relationships between job resources, personal resources, and work engagement. Journal of Vocational Behavior, 74(3), 235-244. doi: 10.1016/j.jvb.2008.11.003

Zhao, H. A. O., Wayne, S. J., Glibkowski, B. C., \& Bravo, J. (2007). The impact of psychological contract breach on work-related outcomes: A meta-analysis. Personnel Psychology, 60(3), 647-680. doi: 10.1111/j.1744-6570.2007.00087.x 